\title{
Improvement of Working Conditions and Opinions of Mine Workers When Battery Electric Vehicles (BEVs) Are Used Instead of Diesel Machines - Results of Field Trial at the Kittilä Mine, Finland
}

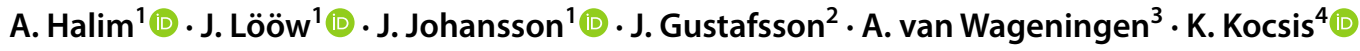

Received: 27 January 2021 / Accepted: 6 October 2021 / Published online: 25 October 2021

(c) The Author(s) 2021, corrected publication 2021

\begin{abstract}
A major part of the European Union's (EU) project Sustainable Intelligent Mining System (SIMS) is investigating the development of diesel-free/carbon-neutral underground mines in order to ensure sustainable underground mining in the future. Replacing diesel machines with electric vehicles in underground hard rock mines has been widely acknowledged by the mining industry worldwide as a critical step to improve working conditions by reducing diesel exhaust-related contaminants, to reduce mine ventilation electrical power cost by reducing mine airflow quantity, and to reduce mine greenhouse gas emissions. All of these are major requirements to achieve sustainable future underground mining practices. A field trial of Epiroc's 2nd generation of Battery Electric Vehicles (BEVs) at Agnico Eagle Finland's Kittilä mine was conducted during 2019-2020. Vehicles tested were MT42 mine truck, ST14 Load-Haul-Dump (LHD), and Boomer E2 jumbo drill rig. This paper outlines the improvement of the working conditions observed in the field trial, and the opinions of the mine personnel at Kittilä mine on using BEVs instead of diesel machines. Measurements of atmospheric contaminants and air temperatures taken during the field trial clearly demonstrated a significant improvement of working conditions when BEVs were operating as opposed to diesel machines. This field observation was supported by the opinion of the majority of the Kittilä mine workers. However, some remaining concerns must be addressed before BEVs can replace diesel machines.
\end{abstract}

Keywords Battery electric vehicles (BEVs) - Occupational health and safety · Working conditions in underground mines . Electrification of underground mines

\section{Introduction}

Replacing diesel machines with electric vehicles in underground hard rock mines has been widely acknowledged by the mining industry worldwide as a critical step to improve working conditions by reducing diesel exhaust-related contaminants, to reduce mine ventilation electrical power cost by reducing mine airflow quantity, and to reduce mine

K. Kocsis is formerly affiliated with the University of Nevada Reno USA

\footnotetext{
A. Halim

adrianus.halim@1tu.se

Luleå University of Technology, Luleå, Sweden

Epiroc AB, Örebro, Sweden

Agnico Eagle Finland Oy, Kiistala, Finland

University of Utah, Salt Lake City, USA
}

greenhouse gas emission. All of these are major requirements of sustainable underground mining practices. Unlike diesel machines, electric vehicles do not produce toxic gases and diesel particulate matter (DPM). In addition, they produce significantly less heat than their diesel counterparts because of their much higher efficiency. They are also less noisy. The vehicles powered by battery and trailing cable produce less water vapor because moisture is not a product of combustion. Improved working conditions underground also have the potential to make the mining industry a more attractive workplace of choice [1,2], thus addressing the current skill shortage.

Despite these many advantages, only a few underground hard rock mines worldwide use electric vehicles, mostly because the electric vehicles traditionally available on the market are cable-trailed load-haul-dump (LHD) units and trolley-assisted trucks. Cable-trailed LHDs are inflexible and operate on a single working level for a considerable period. It is impractical to move 
them to another level because this requires relocating transformers and electric cables. As a result, their application is limited to mines that use panel caving/block caving, large-scale sublevel caving, and other mining methods where the loading horizon stays on one level for a considerable period. Trolley-assisted trucks require expensive fixed overhead trolley lines, thus limiting their range. Moreover, the road surface must be very level to allow the pantograph to stay in contact with the overhead wires. This means the roads require more maintenance than the normal underground mine roads, increasing the mine maintenance costs.

With the recent developments in battery technology, reliable battery electric vehicles (BEVs) have been manufactured since 2016. This new generation of BEVs has the same flexibility as diesel machines. They can be used in all mining methods, including those that require regular movement between working levels, such as sublevel stoping, cut and fill, small/medium-scale sublevel caving, and room and pillar, and they can operate on average mine roads. However, these machines must be tested in real mine conditions to prove their viability and to make a business case for their use. Therefore, a field trial program for these vehicles was performed at the Kittilä mine in Finland as part of the European Union's (EU) Sustainable Intelligent Mining System (SIMS) project [3]. Vehicles included in this trial program were Epiroc's MT42 Battery mine truck, ST14 Battery Load-Haul-Dump (LHD), and Boomer E2 Battery jumbo drill rig. This paper outlines the improvement of working conditions with respect to the air quality and air temperatures inside a working area observed in this field trial, as well as the results of a survey distributed among Kittilä mine employees to capture their opinions on the BEVs.

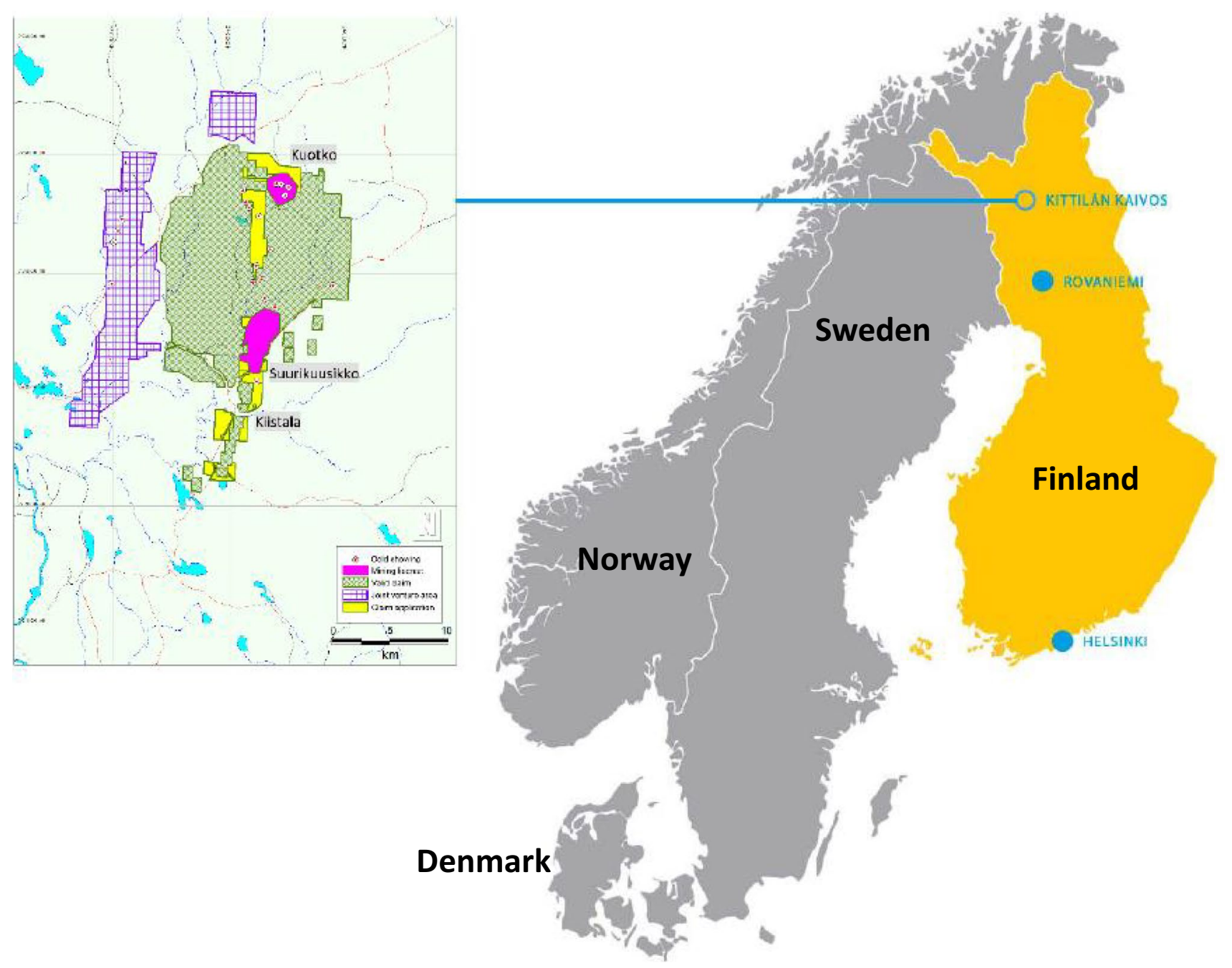

Fig. 1 Location of Kittilä mine site (Kittilän kaivos on the map. The city of Rovaniemi is located about 6 km south of the Arctic Circle) 


\section{Description of the Trial Site}

The Kittilä gold mine, owned by Agnico Eagle Finland Oy, a subsidiary of Agnico Eagle Mines Ltd. of Canada, is located near the village of Kiistala in Kittilä municipality in Lapland, Northern Finland, about $150 \mathrm{~km}$ inside the Arctic Circle, and about $900 \mathrm{~km}$ north of the capital city of Helsinki. It is the largest gold mine in Europe, producing about 1.6 million tonnes per annum (Mtpa) of gold ore that yields $7000 \mathrm{~kg}$ of gold annually [4]. The underground mine uses the sublevel stoping method with paste backfilling to extract the ore reserves. Operations are expected to continue until 2034. Operations began in 2008 with two open pits, the Suuri and Roura orebodies. In October 2010, the mine commenced underground mining operations. When open pit mining ended in 2012, Kittilä became an underground-only operation. The orebodies being mined are Rimpi, Roura, Suuri, and Etelä.

Figure 1 shows the location of the mine site. At the time of the writing of this paper, the mine employed 482 people, with a 40:60 ratio of white to blue collar workers. Most live in the Kittilä municipality, particularly around Levi, the largest ski resort in Finland, about $40 \mathrm{~km}$ from the mine site.

The trial of the ST14 Battery and the MT42 Battery took place mainly on level 150 in the Suuri orebody (level S150), located at a mining depth of $150 \mathrm{~m}$ below the surface, as shown in Fig. 2. Both machines were used to transport broken ore and waste rock from the stopes and level developments to surface stockpiles. They traveled from this level to surface stockpiles via the main ramp. The battery swapping and charging stations for ST14 and MT42 were on level 150 in the Roura orebody (level R150), also at a mining depth of $150 \mathrm{~m}$ below the surface, as shown in Fig. 2. The Boomer E2 Battery was trialed in various development faces inside Kittilä mine.

\section{A Note on the Measurements of Air Quality}

The air quality and air temperatures were measured in the trial area of the ST14 Battery and the MT42 Battery. This area was selected because LHDs and mine trucks are the largest and the most mobile mining machines. Hence, they are usually the largest source of atmospheric contaminants within the underground hard rock mine. Contaminants measured were gases, DPM, and respirable dust. Figure 3 shows a plan of level S150 and the measurement locations. Ventilation on this level is provided by a Removex $75-\mathrm{kW}$ auxiliary fan bolted to a bulkhead in the connecting drive

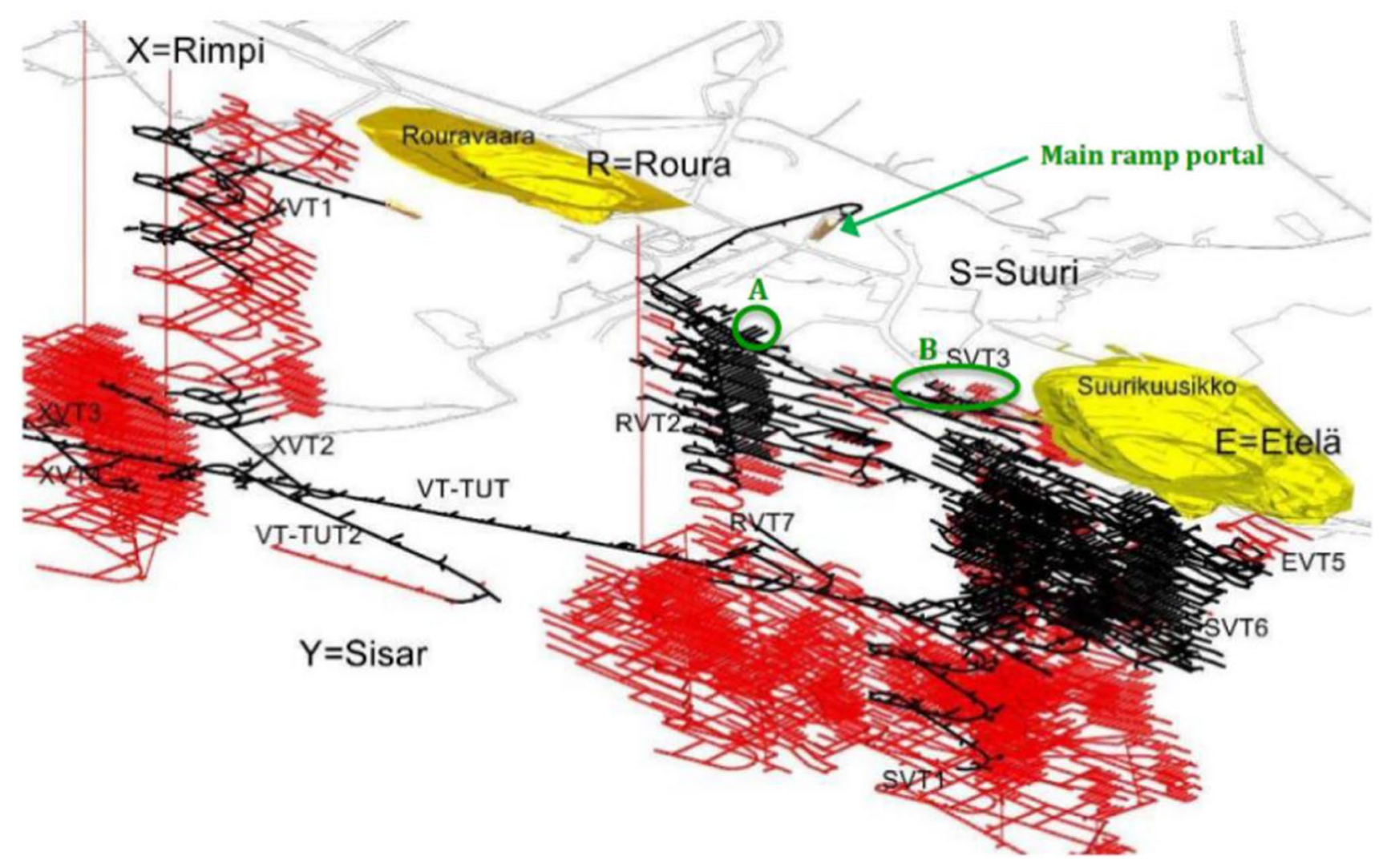

Fig. 2 Location of battery swapping and charging station (A) and main trial site of ST14 and MT42 (B) 


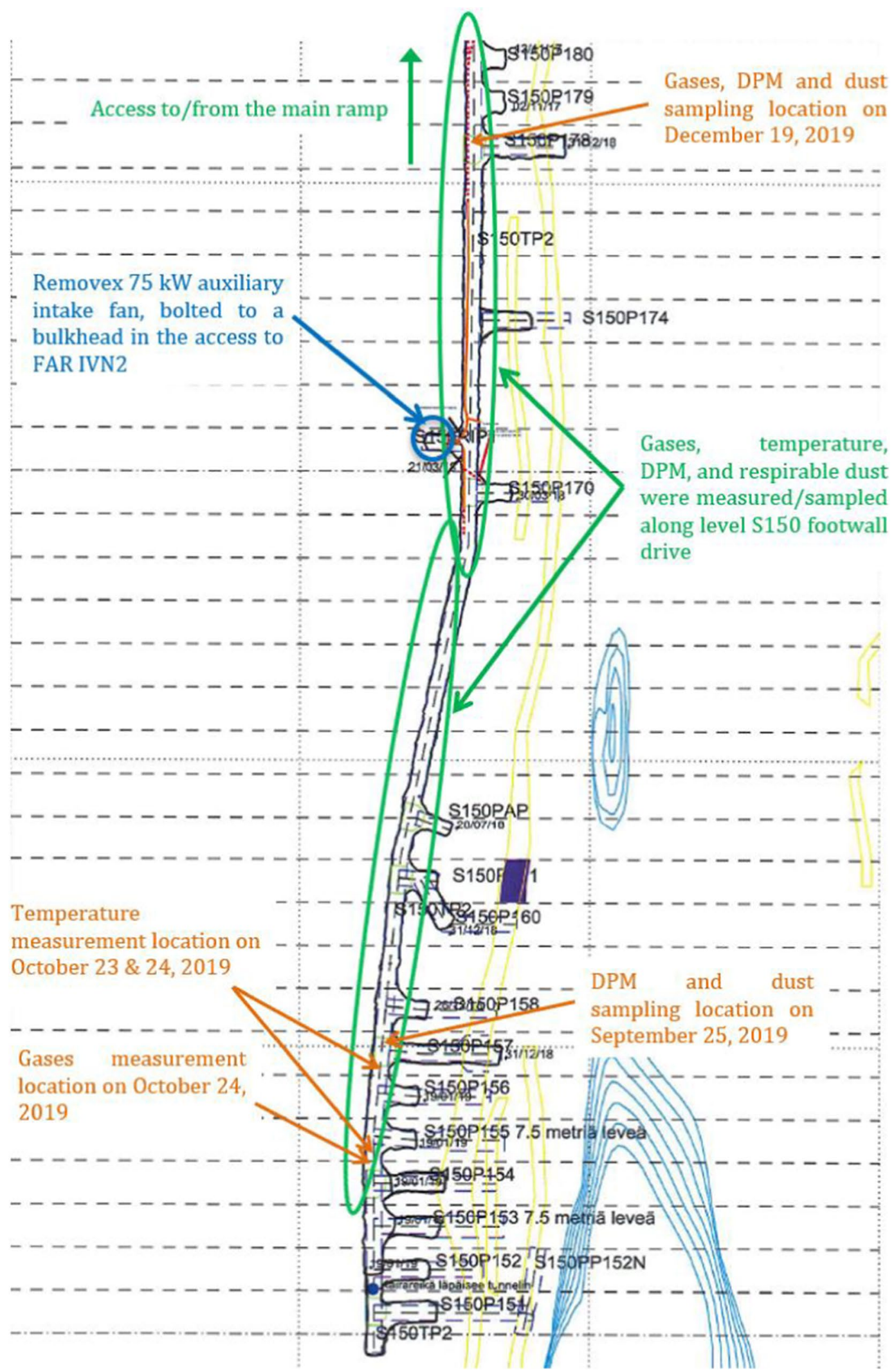

Fig. 3 Plan view of level S150, showing locations of contaminants and temperature measurements 
to the Fresh Air Raise (FAR) IVN2, as shown in Fig. 3. A set of ventilation ducts is connected to this fan. This ducting system distributes the fresh air to the active working area on this level. This fan is equipped with variable speed drive (VSD) to adjust its speed and can deliver about $30 \mathrm{~m}^{3} / \mathrm{s}$ of fresh air at its maximum speed. The air is exhausted into the main ramp, so the footwall drive acts as the main exhaust airway on this level. It must be noted that mines in Nordic countries, including Kittilä mine, use a push-pull primary ventilation system, with exhaust shaft and the main ramp acting as exhaust airways [5]. However, level S150 is located too far from the exhaust shaft at the Suuri orebody (IVN5), as shown in Fig. 4. Therefore, the return air from this level is exhausted only into the main ramp.

Only four measurements of gases and two measurements of temperatures, DPM, and dust could be taken during this trial, mainly because the start of the trial was delayed due to a delay in manufacturing these new BEVs. The delay was understandable because the machines have new technologies that had never been manufactured before. The limited time window to perform measurements significantly restricted the sampling of DPM and dust because it took about 3 months to get the DPM results and about 3 weeks to get the dust results. The DPM samples had to be sent to a laboratory in the USA, whilst the dust samples had to be sent to a laboratory in Helsinki. Moreover, other measurements had to be taken in this trial, such as productivity, operational performance, and energy consumption, all of which took a considerable amount of time. Nevertheless, these measurements are believed to be the first ones taken during a field trial of BEVs in an underground hard rock mine. As such, they provide an interesting picture of the improvement of the air quality inside a working area when BEVs are running. Results of these measurements are outlined in Section 5.

\section{Description of the Tested Battery-Powered LHD and Mine Truck}

The tested battery-powered LHD and mine truck were Epiroc's ST14 Battery and MT42 Battery, respectively. At the time of the field trial, these two BEVs were the largest battery-powered LHD and mine truck in the world. Recently, however they have been surpassed by Sandvik's LH518B LHD and TH550B mine truck, and Artisan's Z50 mine truck.

Epiroc's ST14 Battery LHD is a 14-tonne payload LHD fitted with a liquid-cooled ABB 200-kW electric traction motor and a liquid-cooled ABB $160 \mathrm{~kW}$ electric auxiliary motor. It is designed to have the same exterior dimensions and appearance as the ST14 diesel LHD. However, the diesel engine is replaced by two electric motors (one traction and one auxiliary), and the battery system occupies the space where the diesel engine used to be. Specifications for this LHD are provided through the webpage link [6]. Figure 5 shows a photo of this vehicle inside Kittilä mine.

Epiroc's MT42 Battery mine truck is a 42-tonne payload haul truck fitted with two liquid-cooled ABB 200$\mathrm{kW}$ rated electric traction motors and a liquid-cooled ABB 160-kW electric auxiliary motor. Like the ST14

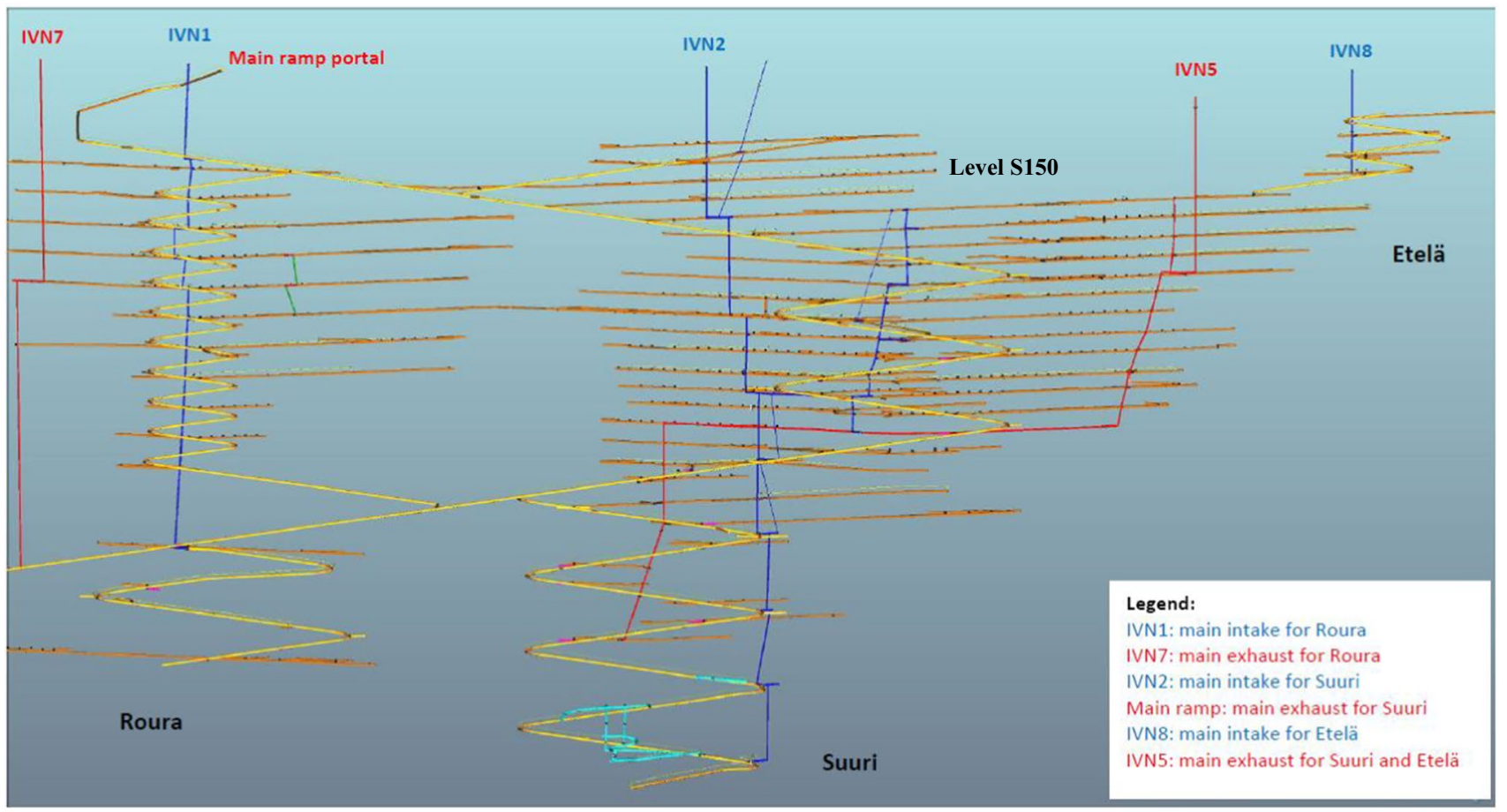

Fig. 4 Long section of Kittilä primary ventilation circuit, showing level S150 
Fig. 5 ST14 Battery during the field trial in Kittilä mine

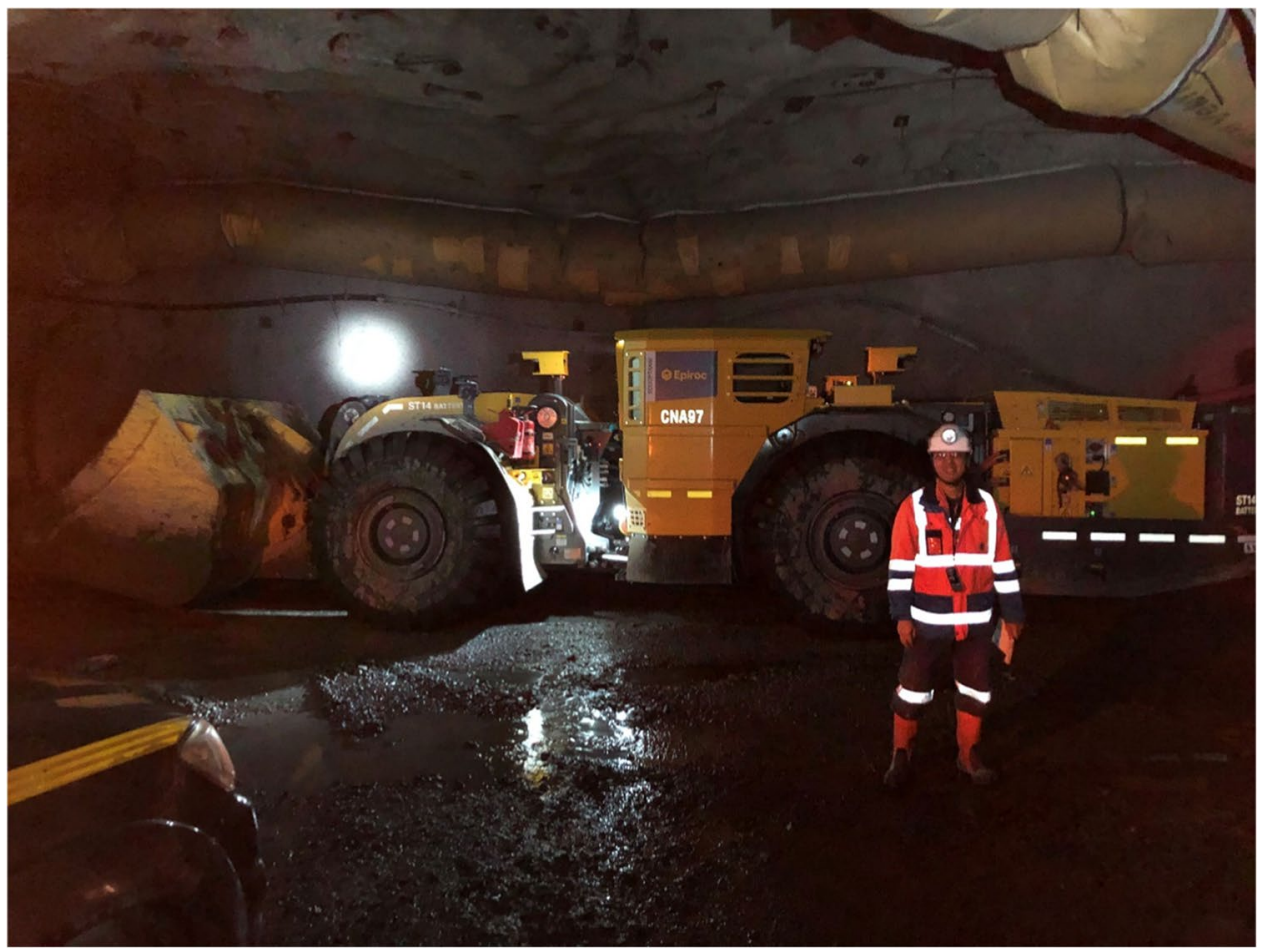

Battery LHD, it is designed to have the same exterior dimensions and appearance as the MT42 diesel mine truck; in this case, the diesel engine is replaced by three electric motors (two traction and one auxiliary), and the battery system occupies the space previously occupied by the diesel engine. Specifications for this truck are provided through the webpage link [7]. Figure 6 shows a photo of this vehicle near the surface stockpile of Kittilä mine.

Fig. 6 MT42 Battery during the field trial in Kittilä mine (courtesy of Epiroc AB)

\section{Improvement in Mine Air Quality Inside Working Areas (See Measurement Locations in Fig. 3)}

\subsection{Gases}

Gases generated by production activities were measured using Dräger X-am 5600 monitors, as shown in Fig. 7. The measured gases were assessed against their prescribed concentration

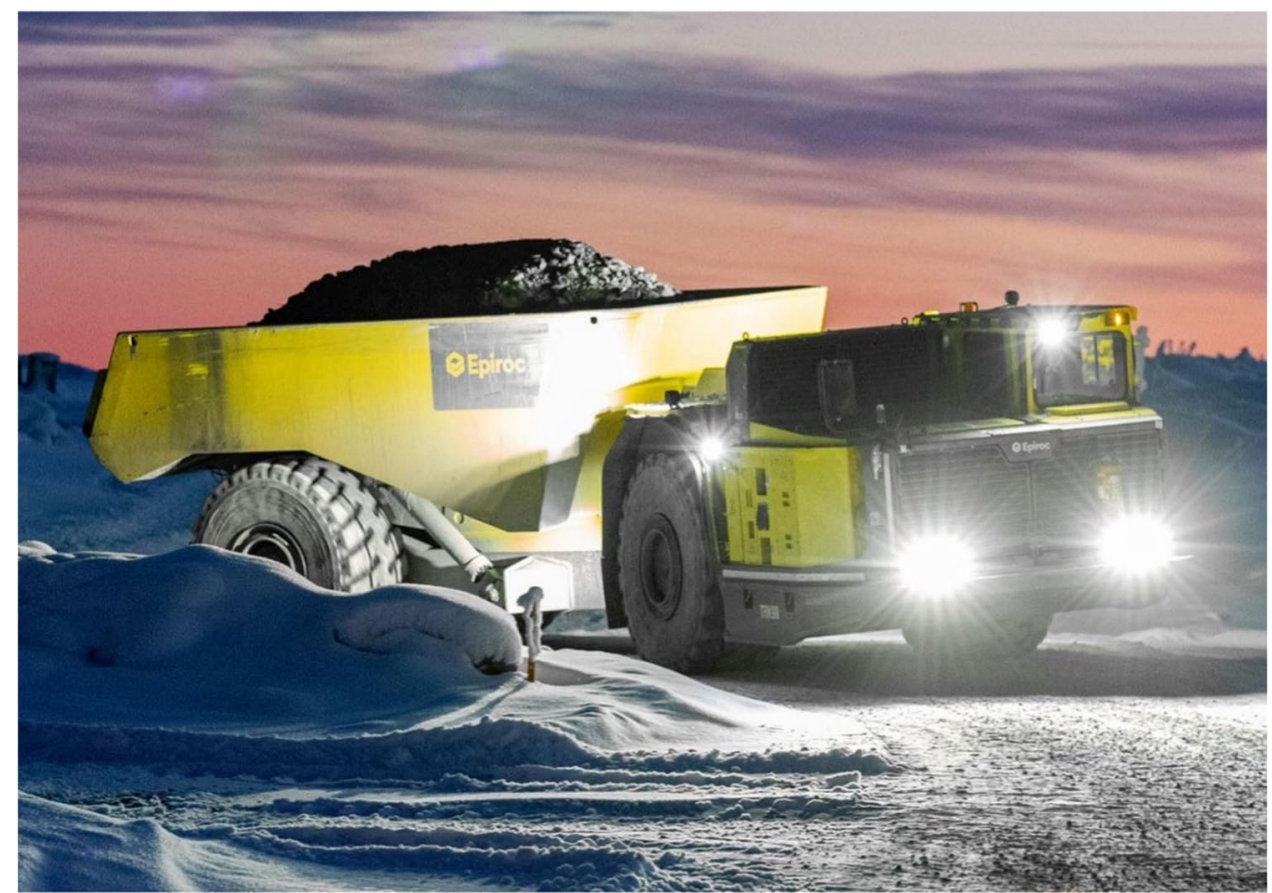


limit given in HTP (Haitallisiksi tunnetut pitoisuudet) Arvot, translated into English as "The list of harmful concentrations of impurities in workplace air," issued by Finnish Ministry of Social Affairs and Health on July 23, 2018 [8]. This limit is the threshold limit value - time weighted average (TLVTWA) for the diesel exhaust gases $\mathrm{NO}_{2}(0.5 \mathrm{ppm})$ and $\mathrm{CO}$ (20 ppm). It must be noted that the TLV-TWA for impurities in workplace air issued by Finnish government is the same as the TLV-TWA prescribed in the EU directives because of Finland's membership in the EU. The above values were adopted from EU Directive 2017/164 issued on January 31, 2017 [9]. The limit for $\mathrm{NO}_{2}$ is significantly lower than the limit in the previous list, $1 \mathrm{ppm}$, issued on November 30, 2016 [10]. This change also applies to other EU members, such as Sweden [5]. Because of the magnitude of the change, the EU granted a transition period until August 21, 2023, for EU mines to comply [5]. Thus, Finnish mines are allowed to use the old TLV-TWA of 1 ppm until August 21, 2023. Because the TLV-TWA is only valid for an 8-h working period, the limit in Kittilä mine must be adjusted, as a working shift lasts $10 \mathrm{~h}$. Therefore, the concentration limits for $\mathrm{NO}_{2}$ and $\mathrm{CO}$ were adjusted to $0.7 \mathrm{ppm}$ and $14 \mathrm{ppm}$, respectively, using the Brief and Scala method, as shown in the Appendix.

Two measurements were taken during the day shift on October 24, 2019, in level S150's footwall drive near crosscut P154. A monitor was placed on each side of the footwall drive. Results are shown in Fig. 8. No gases were detected when only the ST14 Battery and the MT42 Battery were operating, whilst gases were detected (peaks in Fig. 8) when diesel machines were running, although they were below their concentration limit. The diesel

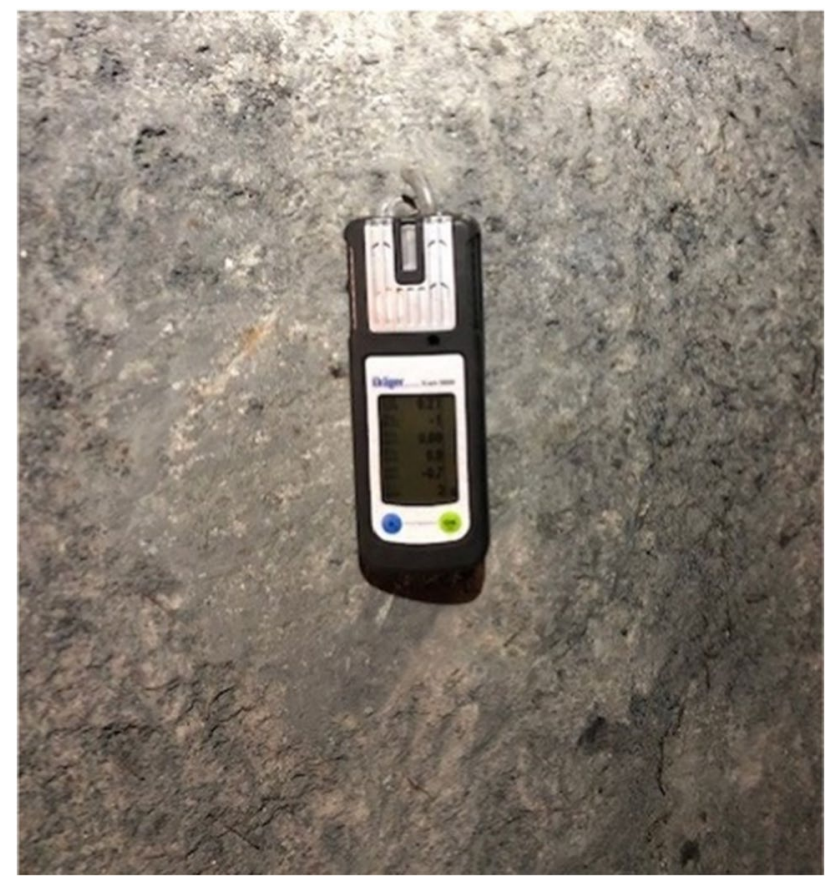

Fig. 7 A photo of gas monitor used to measure gases' concentration during the field trial machines were a Sandvik LH517 LHD and a Scania R560 truck. The other times when no gases were detected were when no machines were running on that level. Two more measurements were taken near crosscut P178 during the day shift on December 19, 2021, when only BEVs were running on level S150 throughout the shift. No gases were detected during this shift. These results are further discussed in Section 7.

\subsection{DPM}

DPM was sampled using a personal sampling unit which included an SKC AirChek TOUCH 220-5000TC pump that draws air into a filter via an SKC GS-1 cyclone fitted with a DPM filter cassette, as shown in Fig. 9. The purpose of the cyclone is to separate the coarse aerosol particles to ensure that only those of size $\leq 1 \mu \mathrm{m}$ will be collected in the filter. The sampling unit, including the pump, cyclone, and filter, was hung on the wall in level S150's footwall drive. The filter was sent to a laboratory in the USA to be analyzed using the NIOSH 5040 method. The analysis revealed an average concentration of DPM throughout the sampling period, shown as the concentration of elemental carbon (EC). Table 1 shows the result of the sample taken on the day shift on September 25, 2019, when only diesel machines (a Sandvik LH517 LHD and few Scania R560 trucks) were running on level S150, and on the day shift on December 19, 2019, when only the ST14 Battery and the MT42 Battery were running on level S150. The laboratory could not detect EC in the December 19 sample. It concluded that this is beyond the lower limit of the analyzer detection capability. Therefore, the laboratory could only estimate the concentration of EC as less than $0.002 \mathrm{mg} / \mathrm{m} .{ }^{3}$ This concentration is very low and can be considered virtually nonexistent. These results are further discussed in Section 7.

Like gases, the measured DPM was assessed against its concentration limit. There is currently no valid TLV-TWA for DPM in Finnish Occupational Health and Safety (OH\&S) regulations or in any EU directives. Kittilä mine adopts the Australian TLV-TWA, $0.1 \mathrm{mg} / \mathrm{m}^{3}$ of EC [11], which was adjusted to $0.07 \mathrm{mg} / \mathrm{m}^{3}$ for Kittilä's working shift using the Brief and Scala method, as shown in the Appendix. As Table 1 shows, the result of the September 25 sample, when only diesel machines were operating on level S150, was below this limit.

It must be noted that the EU is going to prescribe a TLVTWA for DPM of $0.05 \mathrm{mg} / \mathrm{m}^{3}$ of EC starting February 21, 2026 [12]. This will subsequently be adopted by Kittilä and other Finnish mines.

\subsection{Respirable Dust}

Respirable dust was sampled using a unit similar to that used to measure DPM. The only difference was that the filter cassette in the cyclone separated particles of size $\leq 3 \mu \mathrm{m}$ to be collected in the filter. The filter was then sent to a laboratory 


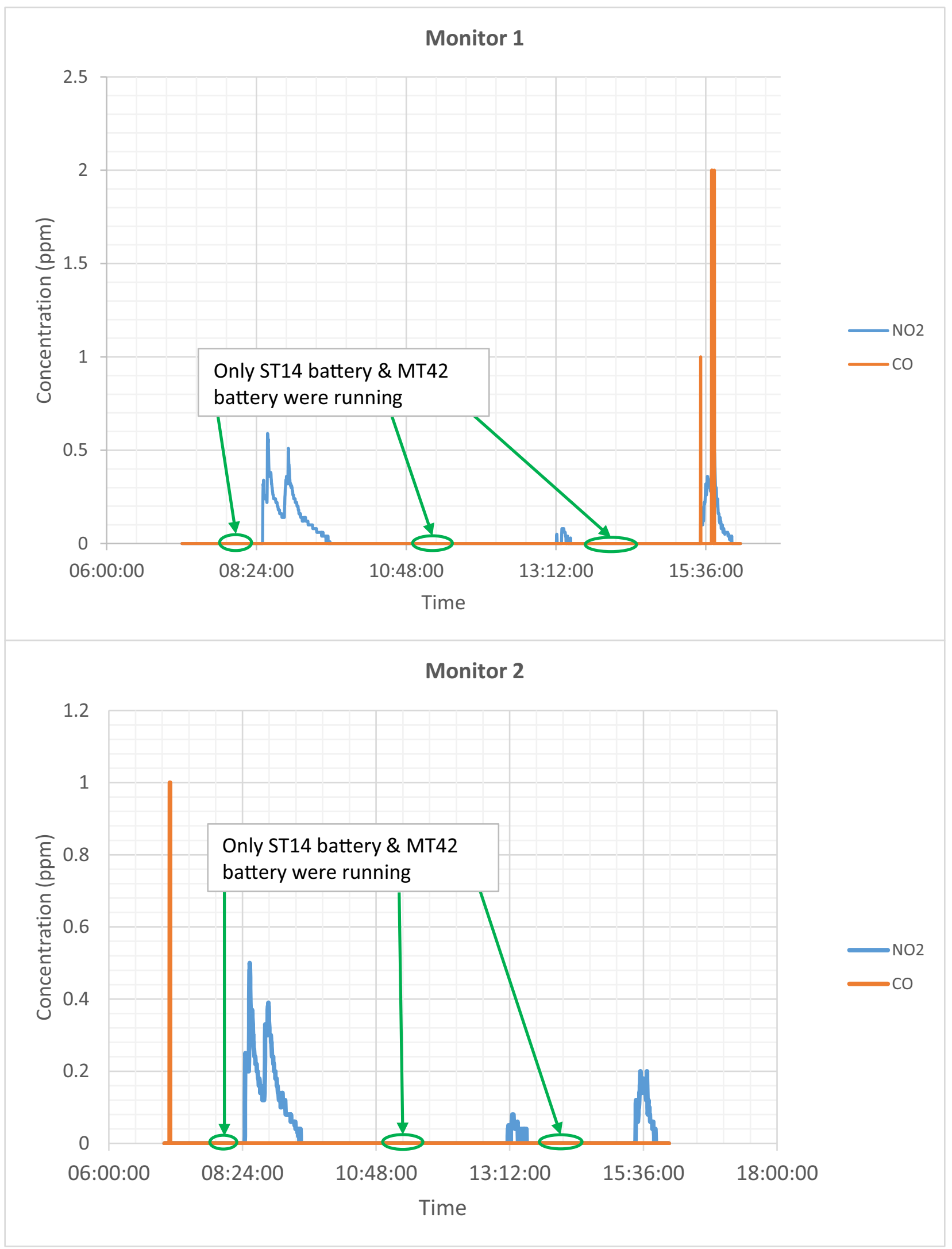

Fig. 8 Gases' concentration in level S150's footwall drive near crosscut P154 on October 24, 2019, day shift 


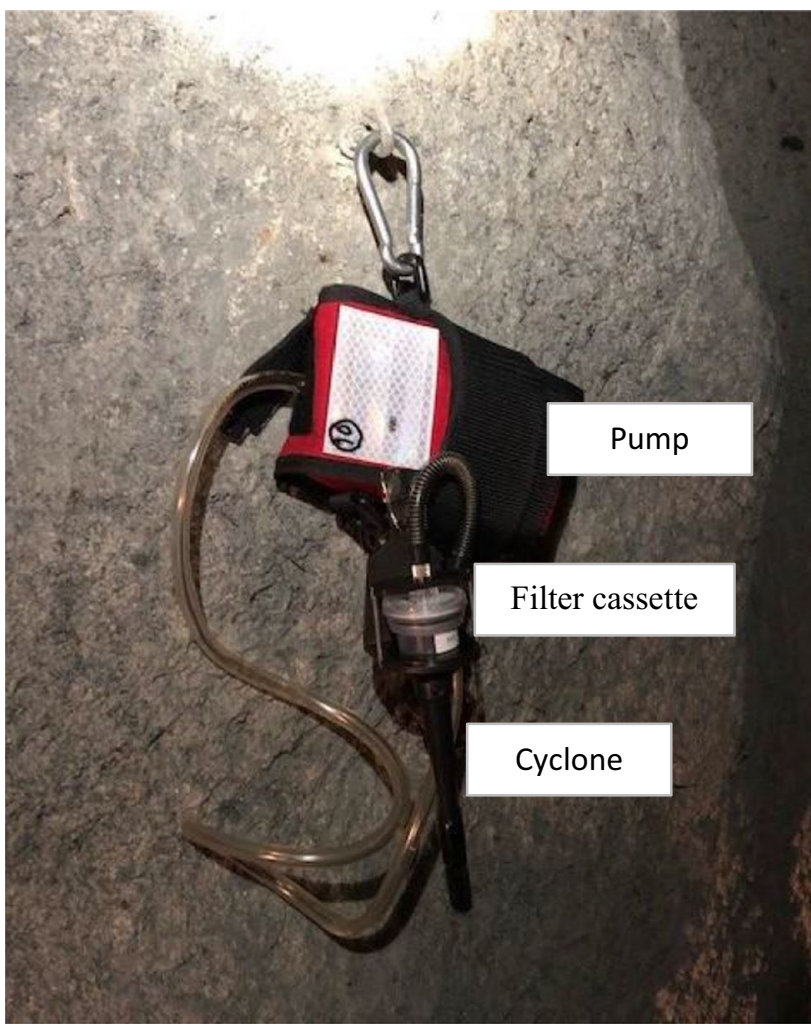

Fig. 9 A photo of the instrument used to measure DPM

in Helsinki. Analysis found average dust concentrations (straight concentration for respirable fraction) throughout the sampling period. Table 2 shows the results. The samples were taken on the day shift on December 19, 2019, when only the ST14 Battery and the MT42 Battery were running on level S150 and on the day shift on September 25, 2019, when only diesel machines (a Sandvik LH517 LHD and few Scania R560 trucks) were running on level S150. The table shows that the dust concentration was significantly lower when BEVs were running. This might reflect the lower tonnage of broken rock moved by the BEVs (368 tonnes) than by the diesel machines ( 403 tonnes). It is also possible that dust on the footwall drive wall was stirred up by the exhaust gases blown out of the diesel machines' tailpipe. These results are further discussed in Section 7. It must be noted that level S150 was constantly wet during the trial period, as a significant amount of groundwater was flowing into it. The water greatly assisted the dust suppression.

Table 1 DPM measurement results

\begin{tabular}{ll}
\hline Only BEVs running on level S150 & $\begin{array}{l}\text { Only diesel machines } \\
\text { running on level S150 }\end{array}$ \\
\hline December 19,2019 & September 25,2019 \\
\hline $\begin{array}{l}\text { Estimated to be less than } 0.002 \mathrm{mg} / \mathrm{m}^{3} \text { of EC } \\
\text { (virtually non-existent) }\end{array}$ & $0.046 \mathrm{mg} / \mathrm{m}^{3}$ of EC \\
\hline
\end{tabular}

Table 2 Respirable dust measurement results

Only BEVs running on level S150

Only diesel machines running on level S150

December 19, 2019 September 25, 2019

$0.09 \mathrm{mg} / \mathrm{m}^{3}$ $0.49 \mathrm{mg} / \mathrm{m}^{3}$

Like gases and DPM, the measured dust was assessed against its concentration limit. There is currently no TLVTWA for respirable dust (straight concentration for respirable fraction) in Finnish OH\&S legislation. To assess the samples, the TLV-TWA for respirable inorganic dust given in Swedish OH\&S regulations (Arbetsmiljöverkets författningssamling - AFS 2018:1), $2.5 \mathrm{mg} / \mathrm{m}^{3}$, was used [13], adjusted to $1.75 \mathrm{mg} / \mathrm{m}^{3}$ for Kittilä's working shift using the Brief and Scala method, as shown in the Appendix. As Table 2 indicates, both samples were below this limit.

\subsection{Air Temperatures}

ACR data loggers were used to measure air temperatures, as shown in Fig. 10. These instruments measure dry bulb (DB) temperatures, barometric pressure (Bar P), and relative humidity $(\mathrm{RH})$. Since the instruments do not measure wet bulb (WB) temperatures, WB temperatures were calculated using psychrometric equations, with DB temperatures, Bar P, and RH as input data. Figure 11 shows measured DB temperatures and calculated WB temperatures.

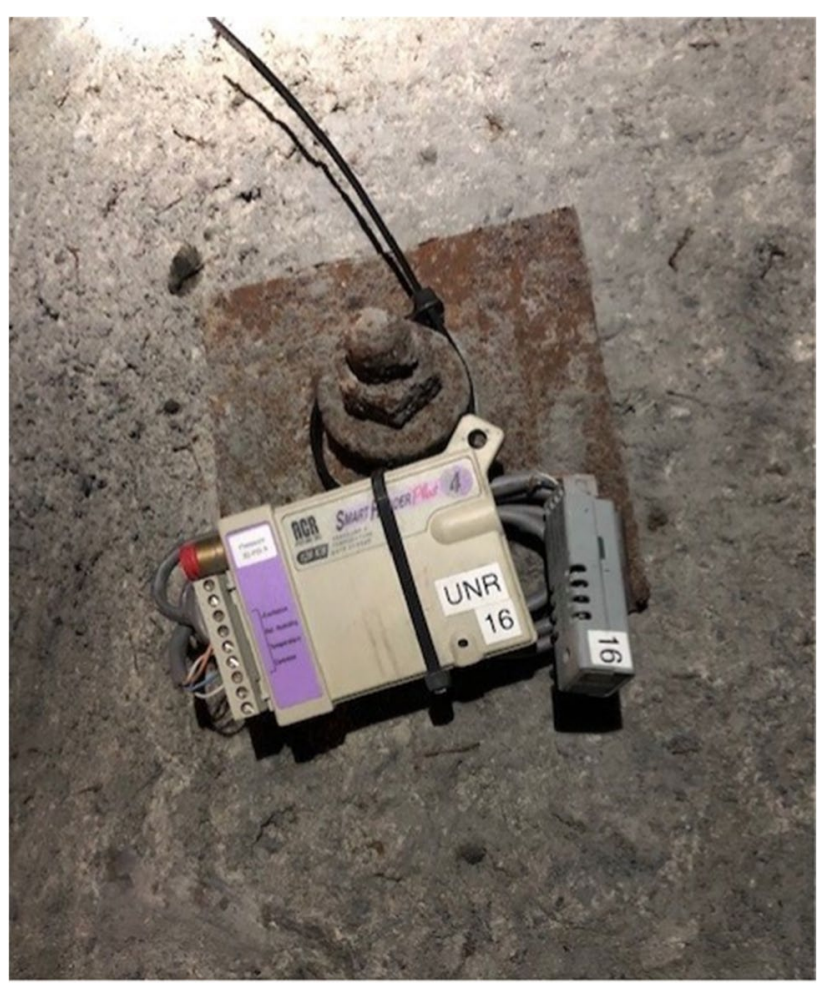

Fig. 10 A photo of an ACR data logger 


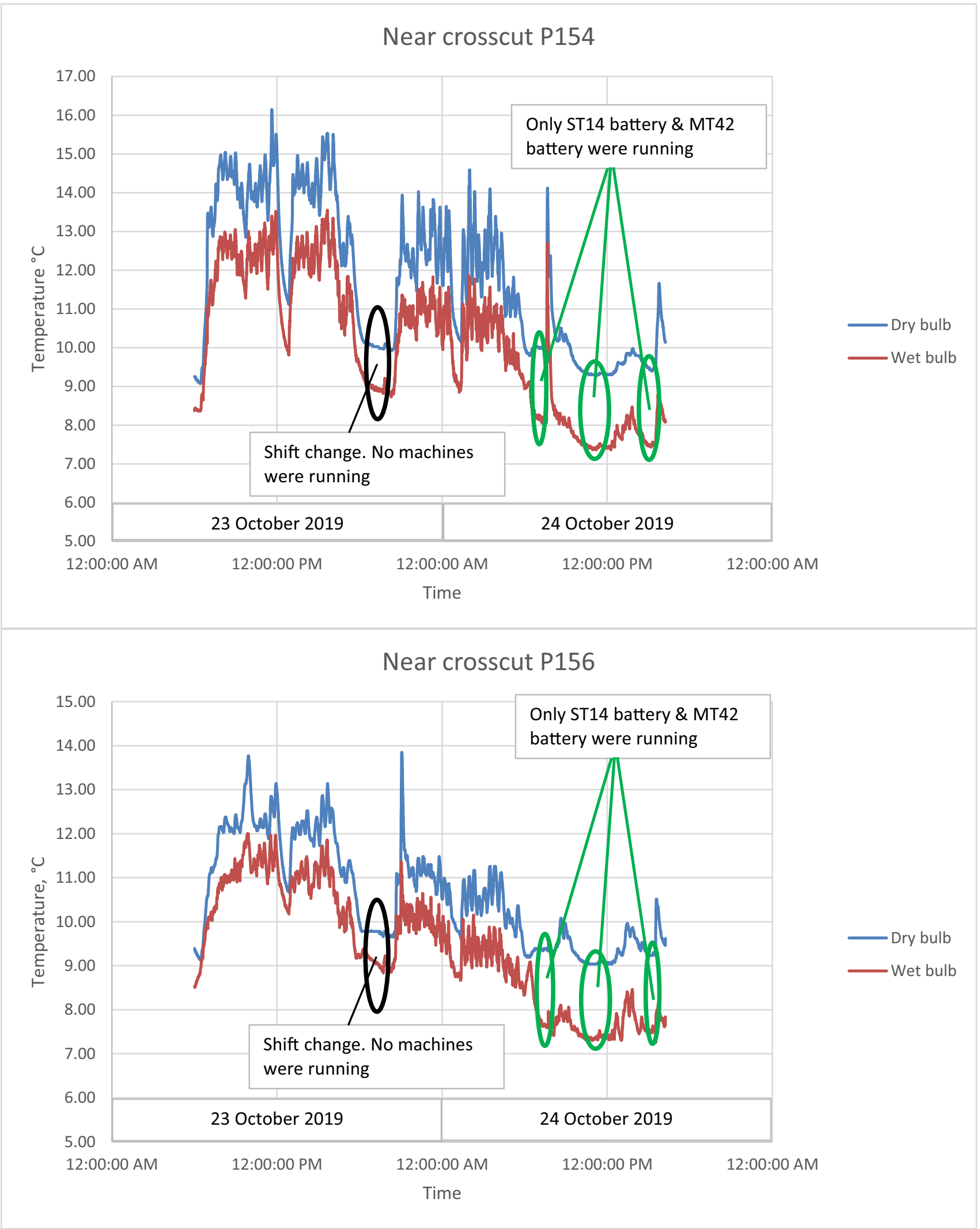

Fig. 11 Dry and wet bulb temperatures in level S150's footwall drive near crosscuts P154 and P156 from October 23, 2019, day shift, until October 24, 2019, day shift. High peaks mean that only diesel machines were running 
It shows the temperatures in level S150's footwall drive near crosscuts P154 and P156 from October 23, 2019, day shift, until October 24, 2019, day shift. The high temperatures $\left(10\right.$ to $16{ }^{\circ} \mathrm{C}$ DB and 9 to $\left.13{ }^{\circ} \mathrm{C} \mathrm{WB}\right)$ were recorded when only diesel machines (a Sandvik LH517 LHD and few Scania R560 trucks) were running. When only the ST14 Battery and the MT42 Battery were running, the temperatures were 9 to $10^{\circ} \mathrm{C} \mathrm{DB}$ and 7.5 to $8{ }^{\circ} \mathrm{C}$ WB. As the figure shows, DB and WB temperatures were both significantly lower when only these two BEVs were running on level S150. This figure also shows that BEVs produce significantly less heat than diesel machines because the WB temperatures were much lower when they were running than when the diesel machines were running.

There is currently no air temperature limit in Finnish OH\&S legislation. Therefore, the limit of $27^{\circ} \mathrm{C} \mathrm{WB}$ was used. This is the typical lower limit of hot working conditions in underground mines used in other countries, including Australia and South Africa. As shown in Fig. 11, the WB temperatures in the trial area ranged from 7 to $13^{\circ} \mathrm{C}$, far below this limit. The level is cold throughout the year because of the sub-Arctic climate on the surface, low Virgin Rock Temperature (VRT), and cold groundwater flow. It must be noted that Kittilä mine currently does not have a heat issue.

\section{Kittilä Mine Workers' Opinion of BEVs}

During the field trial, Kittilä's mine workers were surveyed on their opinions on working conditions when diesel machines are used and changes in the working conditions when BEVs are used. The mine workers who operated the tested BEVs were surveyed; the workers who did not operate the BEVs were also surveyed. Both groups were asked to answer questions on the conditions of the work environment where the BEVs were to operate. The reasons for including both groups are the following: (1) only a few workers operated the BEVs during the trial; (2) research suggests different groups may have important differences in opinion; and (3) the opinions of those who did not operate the machinery in question may help to improve the attractiveness of the mining workplace.

The survey was done in Finnish, since not all mine workers spoke languages other than Finnish. The survey was initially created in Swedish, then translated to Finnish using a translating service. It was double-checked for consistency by a native Finnish speaker employed at Luleå University of Technology. The survey was available online [14]. A mail with a link to the survey was sent out to all relevant employees; the link was also displayed on breakroom information monitors (the underground restaurant/lunchroom has WiFi connectivity, so the mine employees could answer the survey using their smartphones).

The survey was based on an existing survey created by Högskolan Dalarna (Dalarna University) in Sweden to establish the attractiveness of workplaces [15]. The focus on attractive workplaces rather than strictly on health and safety was motivated by the following: (1) health and safety are fundamental aspects of workplace attractiveness; (2) for the mining industry to be sustainable, its workplaces must be attractive. The original survey was modified to fit the field trial. Questions that did not apply to this particular case were removed.

The survey received 47 answers. Of these respondents, 17 operated the tested BEVs. Gender distribution was 5 females and 41 males. One respondent did not disclose gender. The age of the respondents was between 23 and 57, with a mean of 39 .

The survey questions are shown in Table 3. The respondents were asked to rate each statement on a scale from 1 (fully disagree) to 5 (fully agree).

Answers from all respondents are summarized in Table 4 and Figs. 12 and 13. Table 4 shows the mean (average) values of rating for each question displayed in Table 3. Figure 12a summarizes the ratings in percentages for questions on the current working conditions; it includes all respondents. Figure 13a summarizes the ratings in percentages for questions on the improvement of working conditions when BEVs are used; again, it includes all respondents. Figures $12 \mathrm{~b}$ and $13 \mathrm{~b}$ are similar to Figs. 12a and 13a, but only include answers from the respondents who did not operate the tested BEVs. Similarly, Figs. $12 \mathrm{c}$ and $13 \mathrm{c}$ summarize answers from respondents who operated the tested BEVs.

Table 4 shows the majority of the respondents believed using BEVs improves working conditions by increasing air quality, reducing noise level, and reducing risk of contracting work-related illnesses, as underlined by the increase in the mean rating for these aspects. These findings are supported by Figs. 12 and 13 showing the increase in the percentage of respondents who gave ratings of 4 to 5 for these aspects. However, respondents did not believe other aspects (accident risk, work performance, physical effort, mental effort) are improved by switching from diesel machines to BEVs. At the same time, the majority believed BEVs are more modern than existing diesel machines. This response was not surprising, as new machines always have newer technologies.

In addition to the questions shown in Table 3, the respondents were asked what they liked and disliked about the tested BEVs. Their answers are summarized as follows: 
Table 3 Survey questions

\begin{tabular}{|c|c|}
\hline Aspects of the existing working conditions & Question \\
\hline Noise level & Current noise level is low \\
\hline Air quality & Current air quality is good \\
\hline Performance of the existing diesel machines & The existing diesel machines adequately support me in performing my task \\
\hline The existing diesel machines are modern or not & The existing diesel machines are modern \\
\hline Physical effort to complete the task & I can perform my task in the current working conditions with decent physical effort \\
\hline Mental effort to complete the task & I can perform my task in the current working conditions with decent mental effort \\
\hline Safety situation & The risk for accidents to occur is low in the current working conditions \\
\hline Health situation & The risk for contracting work-related illnesses is low in the current working conditions \\
\hline Aspects when BEVs are used & Question \\
\hline Reduction of noisiness when using BEVs & $\mathrm{BEVs}$ reduce noise level \\
\hline Improvement of air quality when using BEVs & BEVs improve air quality \\
\hline Whether BEVs improve the work performance or not & BEVs make it easier to perform my task than the existing diesel machines \\
\hline Modernization of the machineries when using BEVs & BEVs are more modern than the existing diesel machines \\
\hline Physical effort to complete the task & $\mathrm{BEVs}$ reduce the required physical effort to perform my task \\
\hline Mental effort to complete the task & $\mathrm{BEVs}$ reduce the required mental effort to perform my task \\
\hline Improvement of safety situation when using BEVs (BEVs are safer) & The risk for accidents to occur is lower when BEVs are used \\
\hline Improvement of health situation when using BEVs (BEVs are healthier) & The risk for contracting work-related illnesses is lower when BEVs are used \\
\hline
\end{tabular}

Table 4 Mean values of rating for survey questions ( $1=$ fully disagree, $5=$ fully agree $)$

\section{Existing working conditions}

Question

Current noise level is low

Current air quality is good

The existing diesel machines adequately support me in per-

forming my task

The existing diesel machines are modern

I can perform my task in the current working conditions with decent physical effort

I can perform my task in the current working conditions with 3.21 decent mental effort

The risk for accidents to occur is low in the current working conditions

The risk for contracting work-related illnesses is low in the current working conditions

$\begin{array}{ll}\text { Mean rating } & \\ \text { Respondents did not operate BEVs }(n=30) & \text { Respondents operated BEVs }(n=17) \\ 3.47 & 3.76 \\ 3.37 & 3.65 \\ 3.48 & 3.65 \\ 3.79 & 3.65 \\ 3.50 & 3.88 \\ 3.21 & 3.35 \\ 3.38 & 3.47 \\ 2.90 & 3.18\end{array}$

Mean rating

Respondents did not operate BEVs $(n=30)$

3.76

3.65

3.65

3.88

When BEVs are used

Question

Mean rating

Respondents did not operate BEVs $(n=30) \quad$ Respondents operated BEVs $(n=17)$

$\mathrm{BEV}$ s reduce noise level

4.33

4.38

4.30

4.56

3.23

3.19

BEVs make it easier to perform my task than the existing diesel machines

$\mathrm{BEV}$ s are more modern than the existing diesel machines

4.17

4.19

3.19

3.06

3.00

3.28

4.00

$\mathrm{BEVs}$ reduce the required mental effort to perform my task

3.10$$
\text { . }
$$ 
Opinion of current work environment, all $(n=47)$

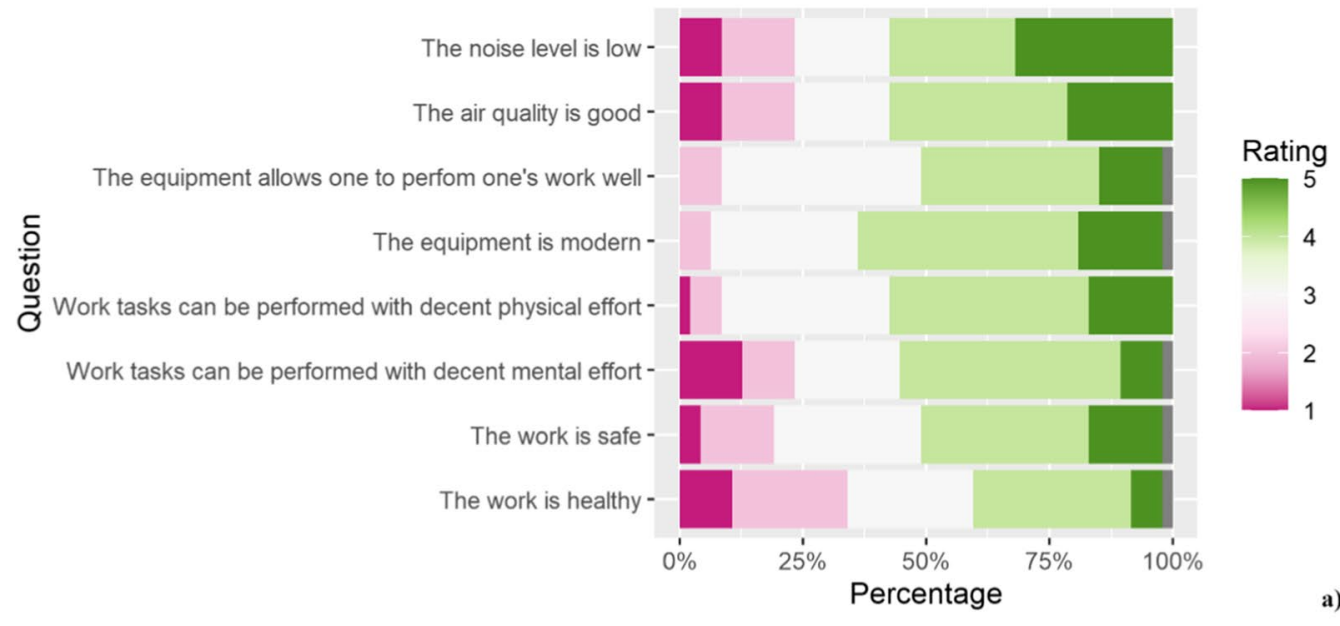

Opinion of current work environment, did not operate BEVs $(n=30)$

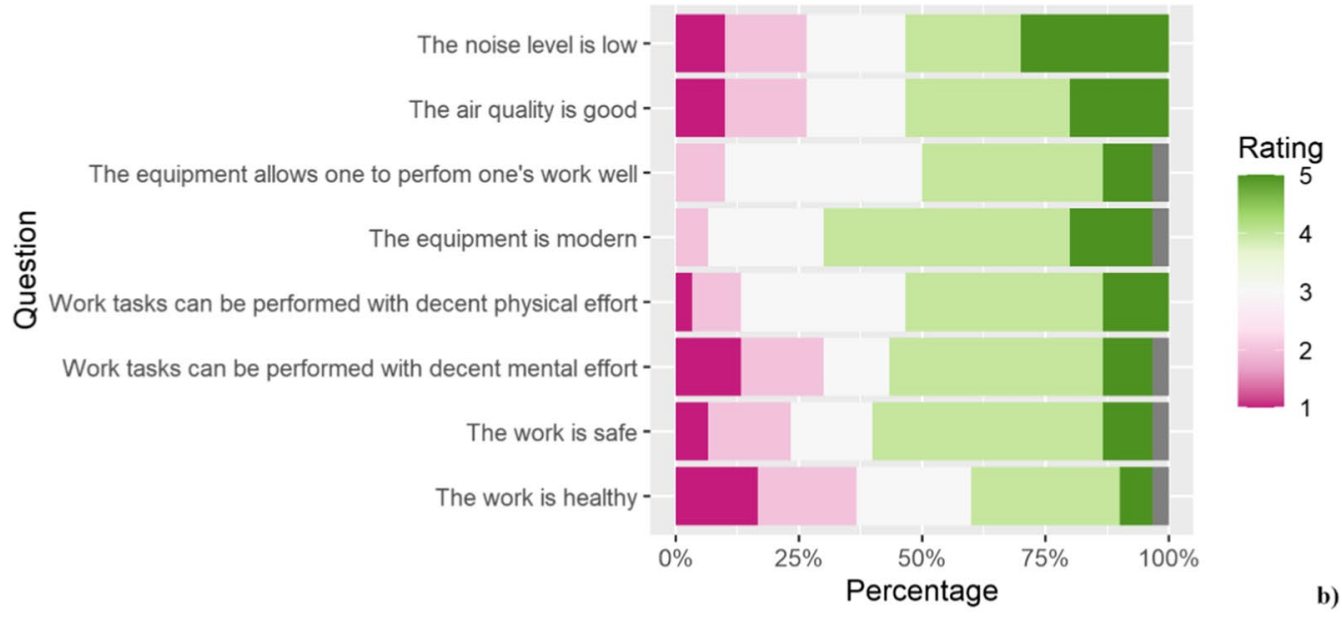

Opinion of current work environment, operated BEVs $(n=17)$

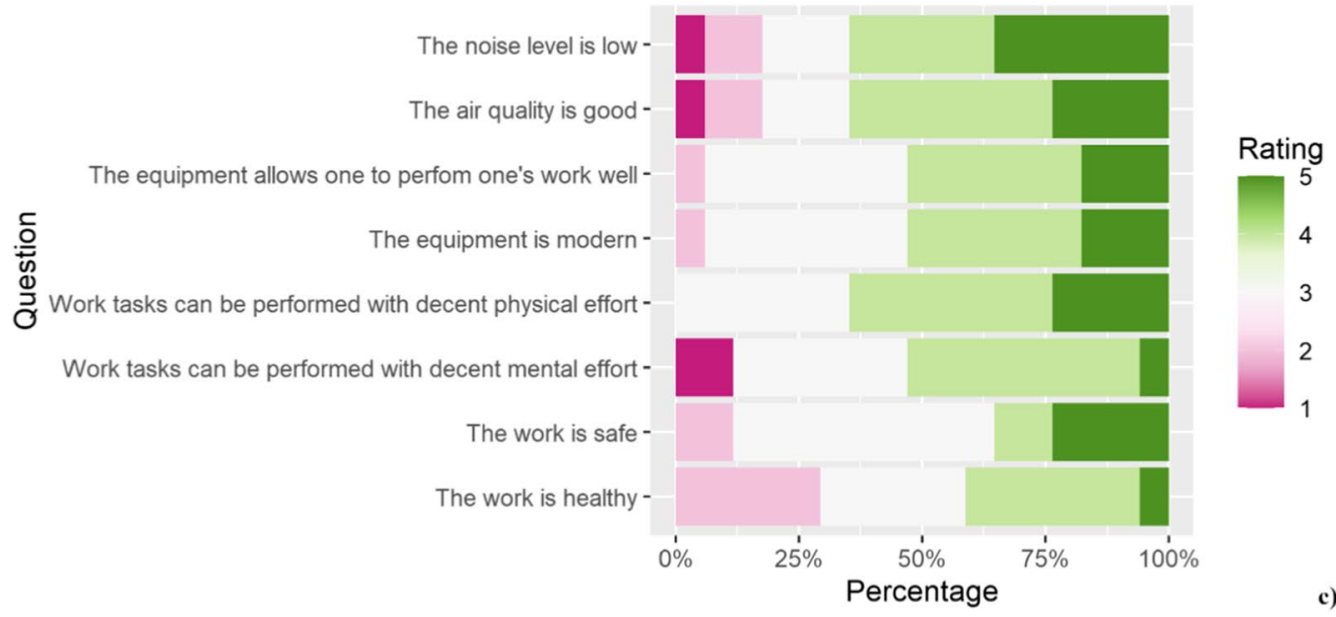

Fig. 12 Summary of ratings in percentages (all respondents) for questions on current working conditions 


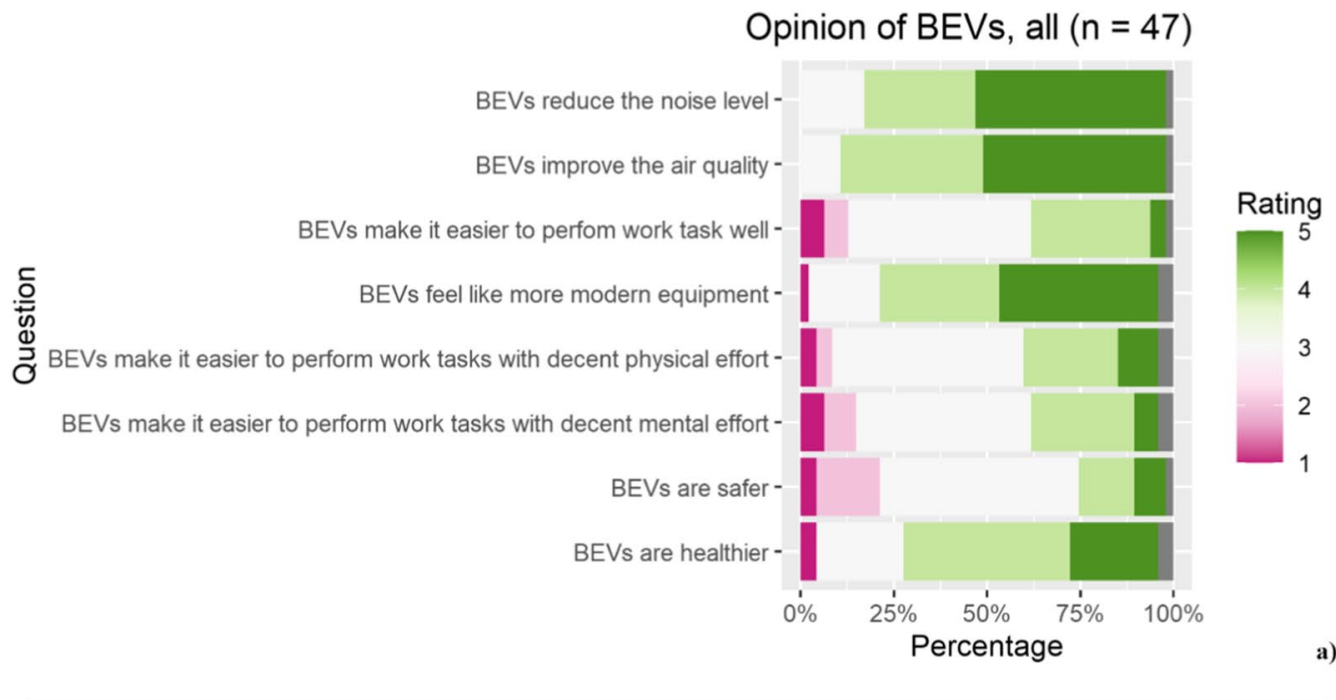

\section{Opinion of BEVs, did not operate BEVs $(n=30)$}

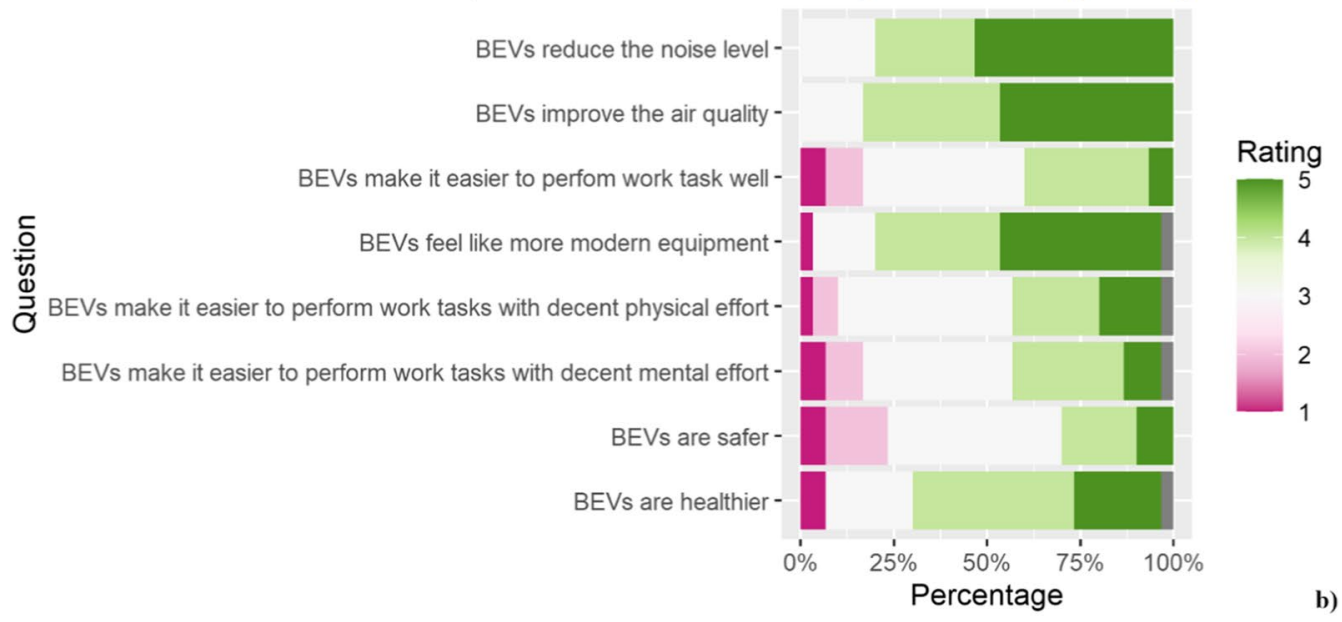

\section{Opinion of BEVs, operated BEVs $(n=17)$}

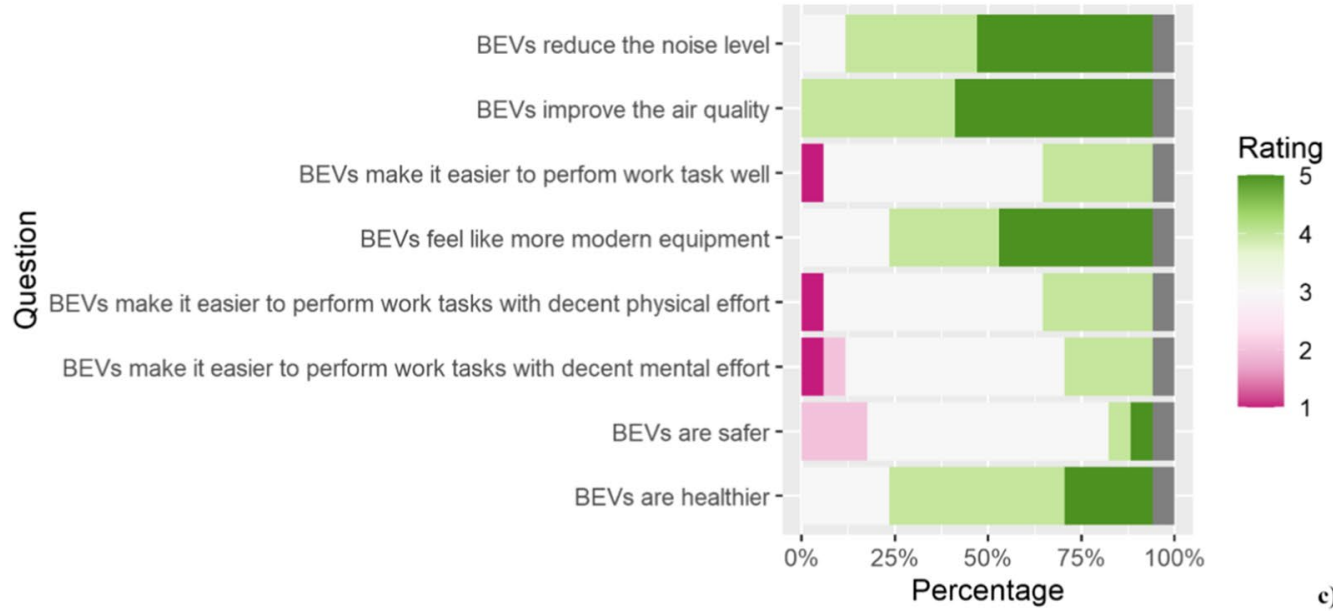

Fig. 13 Summary of ratings in percentages (all respondents) for questions on improvement of working conditions when BEVs are used 
1. Aspects they liked:

- The machines are new and therefore perform better than the existing diesel machines.

- BEVs reduce negative impact on the working conditions by increasing air quality and reducing noise level.

- Because BEVs do not use petroleum products (diesel fuel), they are not affected by Organization of Petroleum Exporting Countries (OPEC).

- BEVs improve the public image of the mine.

- BEVs are less complex than diesel machines because they have fewer moving parts.

2. Aspects they disliked:

- Batteries must be changed frequently.

- The machines are sometimes too quiet. Workers in the vicinity may not hear them and therefore may not be aware of their presence.

- Concern about not enough lithium, cobalt, and copper available to manufacture batteries in the future.

- Work efficiency is lower due to the requirement to change battery frequently

- BEVs are not as user-friendly as diesel machines.

- Concern about electrical-related accidents, such as accidents involving high voltage, electrical fires, and battery fires.

\section{Discussion}

The measurements of gases, DPM, and air temperatures taken during the SIMS project's field trial of BEVs clearly demonstrate a significant improvement in working conditions when BEVs were operating instead of diesel machines. The result was expected because BEVs do not emit gases and DPM and emit less heat than diesel machines irrespective of the workload. However, in the case of dust measurements, even though the concentration when only BEVs were running was significantly lower than when diesel machines were running, we cannot say for sure that using BEVs will lower dust concentration in the air inside a working area, as the type of machine is not the only factor influencing dust concentration. It is also influenced by such factors such as tonnage of the broken rock moved, wetness of the broken rock, and airflow quantity in the loading area. As stated in Section 5.3, level S150 was constantly wet during the trial period, and this greatly suppressed the dust from becoming airborne. Many practitioners agree that preventing dust from becoming airborne is a more effective way to manage it than relying solely on ventilating airflow to dilute it. In fact, supplying too much airflow can worsen the situation because turbulence in the airflow, which is proportional to the airflow quantity, can keep the majority of the dust airborne and onsite.

The observed improvement in working conditions was supported by the Kittilä mine workers. However, some remaining concerns must be addressed before BEVs replace diesel machines. Some were mentioned by the mine workers (see Section 6). Their concerns are understandable: BEVs are new, and the mine workers are not yet familiar with them.

Other concerns were mentioned by management personnel of several mines that are planning to use BEVs, namely Kittilä mine (Finland), Kiruna mine (Sweden), the Boliden area mines (Sweden), KGHM Cuprum mines (Poland), and Creighton mine (Canada). They conveyed these in a separate survey carried out during the SIMS project [16]. This survey was done before the field trial to obtain the insights and opinions of the mining industry worldwide about BEVs. The responses included the concerns mentioned by the Kittilä mine workers, as well as concerns about the business case for using BEVs, mine electrical power management, changes in the training of mine workers, changes in mine management, changes in mine safety procedures, and changes in the mine design.

The business case for using BEVs is very important if mining companies are to replace diesel machines with BEVs. The main concern is productivity. Specifically, BEVs' productivity may be lower than that of diesel machines because of the limited duration of their batteries and the time required to recharge them. As mentioned previously, the productivity of the tested ST14 Battery and MT42 Battery was also measured during the trial. Their productivity was found to be similar to that of their diesel versions. It must be noted that they use battery swapping, which takes around 10 min to complete, instead of battery recharging. Their battery duration is around $4 \mathrm{~h}$, which means that two battery swaps must be done within a working shift. Epiroc is currently improving the swapping tool in order to reduce the swapping time based on the lesson learnt in the field trial.

For Finnish mines and mines located in other EU countries, there is another strong motivation to replace diesel machines with BEVs. As mentioned in Sections 5.1 and 5.2, the EU is going to enforce new TLV-TWAs for $\mathrm{NO}_{2}$ and DPM that are very low, $0.5 \mathrm{ppm}$ and $0.05 \mathrm{mg} / \mathrm{m}^{3}$ of $\mathrm{EC}$, respectively. BEVs are seen by many mines in the EU as the most feasible way to address the challenge of complying with these new concentration limits. Many mines consider using diesel machines makes compliance difficult, even if they are fitted with a Euro VI compliant engine (Euro VI is the cleanest emission standard for heavy vehicle diesel engines sold within the EU and the European 


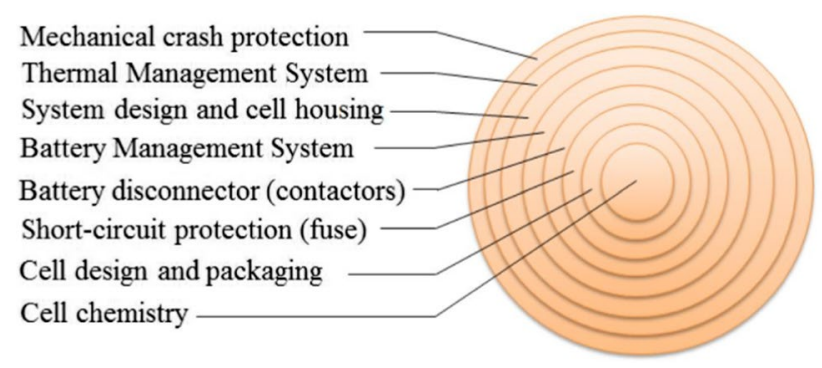

Fig. 14 Battery "Safety Onion" guideline [17]

Economic Area - EEA). The results of the gases and DPM measurements in the field trial show that using BEVs would make it very easy for Kittilä mine to comply with the new limits.

The two surveys mentioned above indicate that the potential for fires related to a BEV's battery and battery charger is the most urgent safety concern. This concern is understandable because these BEVs are new, and their fire safety aspect is not well understood. In fact, the tested BEV battery is designed with fire safety as a priority. The fire safety system follows the "Safety Onion" guideline shown in Fig. 14 [17]. This guideline calls for the provision of multiple layers of fire protection, from the innermost aspect, i.e., the cell chemistry, to the outermost aspect, i.e., protection from mechanical crash. One part of the system, the thermal management system, is essentially a battery cooling system; it prevents overheating and maintains the battery temperature between 25 and $40{ }^{\circ} \mathrm{C}$ [16]. During the trial, the battery did not overheat because of this thermal management system. The battery also obtained a $(\epsilon$ (Conformité Européenne) marking prior to the field trial; this means the battery conforms with the European health, safety, and environmental protection standards and can be legally sold within the EU and the EEA.

Because the tested BEVs are relatively new, their design will evolve to address these concerns. Original equipment manufacturers (OEMs), mining companies, universities, and other R\&D institutions should do more research and development (R\&D) to make BEVs viable mining machines in the near future.

The successful replacement of diesel machines with BEVs may give underground mines an opportunity to reduce their airflow quantity because of the absence of diesel exhaust gases and DPM, and the significantly lower heat produced by BEVs. Reducing airflow quantity will significantly reduce the electrical power required to run ventilation fans and subsequently reduce the ventilation power cost because the fan electrical power is proportional to the cube of airflow quantity. The reduction of airflow quantity might also provide an opportunity to downsize the mine airways and subsequently the airway excavation cost. However, the reduction will be different in each mine due to the presence of strata gases like radon and the magnitude of the heat that comes from sources other than mining machines/vehicles $[18,19]$. Moreover, reducing airflow quantity will extend the blasting re-entry time, and this can reduce mine productivity $[18,19]$. Therefore, reducing airflow quantity and downsizing airways by using BEVs must be very carefully considered.

\section{Conclusion and Recommendations}

The SIMS project field trial of BEVs at the Kittilä mine demonstrated that using BEVs improves working conditions. The survey done during the trial found the mine workers believed using BEVs will make working areas healthier and safer because of the reduction in gases, DPM, and noise. Since the usage of BEVs in underground mining is relatively new, many aspects are not well understood; consequently, mine workers and mine managers still have concerns. More studies must be done to address these concerns and make BEVs viable mining machines from the point of view of operations, health and safety, and economic considerations.

\section{Appendix}

Calculations of concentration limit for a 10-h working shift using Brief and Scala method

Brief and Scala method to calculate concentration limit for working period with duration other than $8 \mathrm{~h}$ is as follows:

Adjusted limit for $h$ working hours per day $=\frac{8 \times(24-h) \times \text { TLV TWA }}{16 \times h}$

Using this method, the concentration limit for a 10-h shift is calculated as seven tenths (0.7) of the TLV-TWA.

Acknowledgements The field trial outlined in this paper received funding from the European Union (EU)'s Horizon 2020 program (Grant Agreement no. 730302). The authors are also grateful to Kittilä mine personnel, in particular, Mr. Jari Kolehmainen, production superintendent; Mr. Tomi Peuraniemi, mining engineer; and Ms. Jaana Halme, occupational hygienist. Constructive feedback from Epiroc personnel, Mr. Ake Kruukka, Mr. Anders Lindkvist, and Mr. Franck Boudreault, is also acknowledged.

Author Contribution A. Halim conducted measurements of atmospheric contaminants and air temperatures and analyzed their results, took photo of ST14 Battery and measurement instruments, and wrote all sections of the paper except the section on the opinions of Kittilä mine workers on BEVs.

J. Lööw and J. Johansson prepared and conducted survey on Kittilä's mine workers, analyzed results of the survey, and wrote the section on opinions of Kittilä mine workers on BEVs.

J. Gustafsson provided all information related to Epiroc AB and reviewed the submitted version of the manuscript. 
A. van Wageningen provided all information related to Agnico Eagle Finland Oy and reviewed the submitted version of the manuscript.

K. Kocsis provided instruments to measure air temperatures, conducted measurements of air temperatures and analyzed their results, and did final editing of the grammars.

Funding Open access funding provided by Lulea University of Technology

\section{Declarations}

Conflict of Interest The authors declare no competing interests.

Open Access This article is licensed under a Creative Commons Attribution 4.0 International License, which permits use, sharing, adaptation, distribution and reproduction in any medium or format, as long as you give appropriate credit to the original author(s) and the source, provide a link to the Creative Commons licence, and indicate if changes were made. The images or other third party material in this article are included in the article's Creative Commons licence, unless indicated otherwise in a credit line to the material. If material is not included in the article's Creative Commons licence and your intended use is not permitted by statutory regulation or exceeds the permitted use, you will need to obtain permission directly from the copyright holder. To view a copy of this licence, visit http://creativecommons.org/licenses/by/4.0/.

\section{References}

1. Johansson J, Johansson B, Lööw J, Nygren M, Abrahamsson L (2018) Attracting young people to the mining industry: six recommendations. Int J Min Miner Eng 9(2):94-108

2. Lööw J, Johansson B, Andersson E, Johansson J (2018) Designing ergonomic, safe, and attractive mining workplaces. CRC Press, Boca Raton, FL

3. Sustainable Intelligent Mining Systems (SIMS) project website. https://www.simsmining.eu/project/battery-driven-equipment/.

4. Agnico Eagle Finland website. http://agnicoeagle.fi/.

5. Halim A, Bolsöy T, Klemo S (2020) An overview of the Nordic mine ventilation system. CIM J 11(2):111-119

6. Epiroc ST14 Battery specification. https://www.epiroc.com/en-ca/ products/loaders-and-trucks/electric-loaders/scooptram-st14-batte ry.

7. Epiroc MT42 Battery specification. https://www.epiroc.com/en$\mathrm{ca} /$ products/loaders-and-trucks/electric-trucks/minetruck-mt42battery.

8. Haitallisiksi tunnetut pitoisuudet (HTP) arvot 2018 (in Finnish). https://julkaisut.valtioneuvosto.fi/bitstream/handle/10024/160967/ STM_09_2018_HTParvot_2018_web.pdf?sequence=1\&isAll owed $=\mathrm{y}$.
9. European Union Commission (2017). Commission Directive (EU) 2017/164 of 31 January 2017 establishing a fourth list of indicative occupational exposure limit values pursuant to Council Directive 98/24/EC, and amending Commission Directives 91/322/ EEC, 2000/39/EC and 2009/161/EU (Text with EEA relevance). http://data.europa.eu/eli/dir/2017/164/oj.

10. Haitallisiksi tunnetut pitoisuudet (HTP) arvot 2016 (in Finnish). https://julkaisut.valtioneuvosto.fi/bitstream/handle/10024/79109/ 08_2016_HTP-arvot_suomi_22122016_netti_kansilla.pdf?seque nce $=1 \&$ is Allowed $=$ y.

11. Government of Western Australia (2013). Guideline on management of diesel emissions in Western Australian mining operations. http://www.dmp.wa.gov.au/Documents/Safety/MSH_G_Diese 1Emissions.pdf.

12. European Union Commission (2019). Directive (EU) 2019/130 of The European Parliament and of The Council of 16 January 2019 amending Directive 2004/37/EC on the protection of workers from the risks related to exposure to carcinogens or mutagens at work. https://eur-lex.europa.eu/legal-content/EN/TXT/PDF/? uri $=$ CELEX:32019L0130\& from $=$ FR.

13. Arbetsmiljöverket (2018). AFS 2018:1 Hygieniska gränsvärden (in Swedish). https://www.av.se/globalassets/filer/publikationer/ foreskrifter/hygieniska-gransvarden-afs-2018-1.pdf.

14. Kittilä mine survey questionnaire regarding BEVs (in Swedish). https://docs.google.com/forms/d/16V2FddrsCamSNBXOpYU zMfJbnIFcF5YEdWyLjq8TFEQ/edit.

15. Högskolan Dalarna (2004). Frågor om Attraktivt Arbete (in Swedish). http://www.diva-portal.org/smash/get/diva2:278867/ATTAC HMENT01.pdf.

16. Halim, A. (2019). Economic impact and impact to the environment measurement by replacing diesel vehicles with battery powered ones. Confidential report to the European Union (EU) Commission as a deliverable of Sustainable Intelligent Mining Systems (SIMS) project.

17. Larsson, F. (2017). Lithium-ion battery safety - assessment by abuse testing, fluoride gas emissions and fire propagation $(\mathrm{PhD}$ thesis). Chalmers University of Technology, Sweden. Retrieved from https://publications.lib.chalmers.se/records/fulltext/251352/ 251352.pdf.

18. Halim, A. (2020). WP6 Final Report. Confidential report to the European Union (EU) Commission as a deliverable of Sustainable Intelligent Mining Systems (SIMS) project.

19. Gyamfi, S., Halim, A., and Martikainen, A. (2021). Development of strategies to reduce ventilation and heating costs in a Swedish Sublevel Caving mine - a unique case of LKAB's Konsuln mine. https://doi.org/10.1007/s42461-021-00483-y.

Publisher's Note Springer Nature remains neutral with regard to jurisdictional claims in published maps and institutional affiliations. 